\title{
Vehicle ownership and mode use: the challenge of sustainability
}

\author{
Sivaramakrishnan Srinivasan · Joan L. Walker
}

Published online: 18 April 2009

(C) The Author(s) 2009. This article is published with open access at Springerlink.com

We present to you the 2009 Transportation Research Board (TRB) special issue of Transportation comprising six papers that were presented at the 88th Annual Meeting of the Transportation Research Board. This special issue is an outcome of the partnership between Transportation and the TRB, a division of the National Research Council, which serves the National Academy of Sciences and the National Academy of Engineering in the United States. In particular, two standing committees of TRB's Division A (Technical Activities) are involved in this partnership: The Committee on Traveler Behavior and Values (ADB10) and The Committee on Transportation Demand Forecasting (ABD40). The special issues have been published by Transportation yearly since 2005 and build on TRB's commitment to disseminate cutting-edge research and state-of-the-art solutions in transportation to a worldwide audience.

The theme of this special issue is Vehicle Ownership and Mode Use-the Challenge of Sustainability. This topic was inspired by the increasing emphasis by society on sustainability, in general, and the role of transportation within this broader picture. Indeed, issues of climate change and energy needs are among the biggest challenges currently facing the transportation profession. The quest for sustainable travel has, for better or for worse, been aided recently by historically high fuel prices as well as economic struggles. Together these forces have led to a reduction in vehicle miles of travel and migration of auto buyers from SUV's to more fuel-efficient cars and reduction in auto ownership all together. Driven by this theme of travel behavior and sustainability, six behavioral modeling papers have been selected that deal with the related issues of fuel price, vehicle ownership, and vehicle miles traveled.

\footnotetext{
S. Srinivasan $(\bowtie)$

Department of Civil and Coastal Engineering, University of Florida, 365 Weil Hall, P.O. Box 116580, Gainesville, FL 32611, USA

e-mail: siva@ce.ufl.edu

J. L. Walker

Center for Global Metropolitan Studies, Department of Civil and Environmental Engineering, Institute of Transportation Studies, University of California at Berkeley, McLaughlin Hall, Room 111, Berkeley, CA 94720, USA
} 
The first paper focuses on the variation in car-ownership over time. The next two examine the vehicle ownership and usage decisions using simultaneous-equations-type frameworks. The final three papers all focus on mode choice. The first of these three papers develops mode-choice models that distinguish between choice-riders and car-dependent commuters. The last two articles use market-segmentation analyses to distinguish among various classes of car and transit users.

In the next several paragraphs we provide an overview of each of these studies, briefly presenting the method and emphasizing the findings related to our theme of sustainable travel.

Woldeamanuel et al. examine the variation in household car-ownership levels over time using data from the German Mobility Panel of 1996-2006. Two-way (household-specific and time-specific) random-effects models were developed recognizing the panel nature of the data. The models highlight the impact of several land-use and transportation characteristics on car ownership after controlling for socio-economic characteristics of the household. In particular, the availability of railway stops and shopping opportunities nearby were found to decrease car ownership. Similarly, the respondents' perceptions about parking difficulties and satisfaction with the accessibility to public transportation were also found to impact car ownership levels. The models also indicate significant between-household variance indicating the presence of several unobserved factors which are determinants of household car ownership. At the same time, the within-household variance was minimal.

Barla and colleagues examine auto-ownership (number of light-duty vehicles), usage (kilometers per adult), and fuel consumption rate (liters per kilometer) using aggregate (province-level), panel (1990-2004) data from Canada. Simultaneous-equations models were developed to assess the aggregate price elasticities of gasoline and travel demands. The empirical models indicate that the price elasticity of gasoline demand is -0.12 in the short term and between -0.26 and -0.3 in the long-term. The price elasticity of travel demand was determined to be -0.08 in the short term and -0.2 in the long term. Based on the above, the authors quantify the magnitude of the "rebound effect" to be $8 \%$ in the short term and about $20 \%$ in the long term- this describes why the actual decrease in fuel consumption because of increase in fuel efficiency is less than expected because of a corresponding increase in vehicle usage (also stimulated by increased fuel efficiency).

The third paper in this special issue, by Spissu et al., is also on simultaneously modeling auto ownership and usage. However, these researchers focus on the cross-sectional choices at the household-level unlike their Canadian counterparts who analyzed province-level panel data. A copula-based discrete-continuous model is developed to analyze the type of vehicle (six categories ranging from compact sedan to van) purchased and the mileage driven. The authors apply their model to examine the aggregate impact of a hypothetical change in fuel prices. The results indicate that people will respond to such fuel price increases to a greater extent by shifting vehicle types than by reducing their vehicle usage.

The first three papers in this issue examined car ownership and usage decisions. The next three papers examine mode choice. Sohn and Yun use data from Korea to distinguish between car-dependent commuters and choice-riders in mode-choice analysis. The authors argue that some travelers are simply car-dependent and hence do not make their mode choice decisions based on the classical theory of utility maximization. Their empirical results indicate that the logit model for mode choice (transit or car) can be improved by including only choice-riders in the estimation sample. The support vector machine (SVM) is presented as a methodology to classify users into car-dependent and choice-riders based on "latent" factors such as the decision makers' desire for independence and their perception of convenience. 
The last two papers also seek to segment the travelers based on their relative preferences for the car and transit modes. Cools and colleagues use data from Belgium and the "Q-Methodology" for segmenting travelers. Consistent with the Korean study, the Belgian researchers also uncover a segment of "car-dependent" travelers (who have a very strong preference for the auto mode) whose mode choice behavior is described as "pure routine". Three other segments were also generated; however, these segments did not exhibit such strong attachments to either the car or the auto modes. Based on their results, they found that increasing reliability of public transport, increasing cost of auto travel, and removing psycho-social barriers show the most potential for increasing sustainable travel.

Diana and Mokhtarian use clustering analysis to classify travelers based on the degree of acquaintance (quantified in terms of actual use of that mode) with each of auto and transit modes. Further, they also examine the differences across the user classes, in the travelers' desires to change the volume of travel by each mode. Data from France and United Stated were used in their analysis. Consistent with the results from the previous two papers discussed, these researchers also find clusters with strong "attachments" for one of the modes. At the same time, it is also found that strong users of a mode "like to bring balance to their modal consumption by increasing the use of the alternate mode". This result seems to suggest the possibility of achieving a better modal balance despite the significant auto dependency currently observed.

The papers in this issue have used data from different parts of the world: Germany, Canada, United States, Korea, Belgium, and France. The analysis methodologies span from classification techniques such as cluster analysis, SVM, and "Q-Methodology" to econometric methods such as random-effects models, simultaneous equations, and discrete-continuous models. They also reflect the wide variety of influences relevant to sustainable travel behavior, including transport and land use characteristics, demographics, economics, and psychological factors. Together, the papers provide interesting insights into auto-ownership and mode-choice decisions which have substantial implications for formulating and analyzing policies aimed at achieving sustainability in terms of transportation capacity, fuel consumption, and environmental effects.

In summary, these papers, together with the many related papers presented at the TRB Annual Meeting and subsequently published in the Transportation Research Record: Journal of the Transportation Research Board -significantly advance our knowledge of auto-ownership, usage, and mode-choice decisions and also provide the basis for further research in this area.

We wish to acknowledge the efforts of Mark Norman and Kimberly Fisher of the TRB; Martin Richards, the Editor-in-Chief of Transportation; Ram Pendyala, the Chair of The Committee on Traveler Behavior and Values; and Tom Rossi, the Chair of the Committee on Transportation Demand Forecasting in making this special issue possible. We would also like to thank all the contributing authors and anonymous reviewers.

Open Access This article is distributed under the terms of the Creative Commons Attribution Noncommercial License which permits any noncommercial use, distribution, and reproduction in any medium, provided the original author(s) and source are credited.

\section{Author Biographies}

Sivaramakrishnan Srinivasan is an Assistant Professor in the Department of Civil and Coastal Engineering at the University of Florida, Gainesville. His research interests are in the area of developing 
behavioral models to forecast activity-travel patterns for transportation planning and policy analysis. He is a member of the TRB Committee on Traveler Behavior and Values.

Joan L. Walker is an Assistant Professor at UC Berkeley in the Department of Civil and Environmental Engineering and Berkeley's new Center for Global Metropolitan Studies. Her research focus is behavioral modeling, emphasizing methods and their application to urban issues including health, congestion, air quality, equity, and quality of life. Her publications appear in journals of Economics, Geography, Marketing, Social Sciences, and Transportation. She has recently been awarded a Presidential PECASE Award, the nation's highest honor for scientists and engineers beginning their independent careers. 